\title{
Protective Effects of Silymarin Against D-Gal/LPS- Induced Organ Damage and Inflammation in Mice
}

\author{
Xin Zhao $\mathbb{D}^{1-3, *}$ \\ Haoxiang Wang ${ }^{4, *}$ \\ Yue Yang ${ }^{1,5}$ \\ Yuting Gou ${ }^{1,5}$ \\ Zhiying Wang ${ }^{6}$ \\ Dingyi Yang ${ }^{7}$ \\ Chong $\mathrm{Li}^{1-3}$
}

'Chongqing Collaborative Innovation Center for Functional Food, Chongqing University of Education, Chongqing. 400067, People's Republic of China; ${ }^{2}$ Chongqing Engineering Research Center of Functional Food, Chongqing University of Education, Chongqing, 400067,

People's Republic of China; ${ }^{3}$ Chongqing Engineering Laboratory for Research and Development of Functional Food, Chongqing University of Education, Chongqing, 400067, People's Republic of China; ${ }^{4}$ Department of Neurology, Second Affiliated Hospital of Army Medical University, Chongqing, 400037, People's Republic of China; ${ }^{5}$ College of Biological and Chemical Engineering, Chongqing University of Education, Chongqing, 400067, People's Republic of China; ${ }^{6}$ School of Pharmacy, Heilongjiang University of Traditional Chinese Medicine, Harbin, I50040, People's Republic of China; ${ }^{7}$ Key Laboratory for Biorheological Science and Technology of Ministry of Education (Chongqing University), Chongqing University Cancer Hospital \& Chongqing Cancer Institute \& Chongqing Cancer Hospital, Chongqing, 400044, People's Republic of China

*These authors contributed equally to this work

Correspondence: Chong Li; Dingyi Yang Tel +86-23-6265-3650

Email lichong@food.ac.cn;

20627622@qq.com
Aim: Silymarin contains various flavonoids and exhibits antioxidative, anti-inflammatory, and anticancer effects, in addition to other pharmacological properties. This study explored the alleviating effect of silymarin on multiple-organ damage induced by D-galactose/lipopolysaccharide in Kunming mice.

Methods: Kunming mice were injected intraperitoneally with D-galactose (30 $\mathrm{mg} / \mathrm{kg} \cdot \mathrm{BW}) /$ LPS $(3 \mu \mathrm{g} / \mathrm{kg} \cdot \mathrm{BW})$ and then treated using silymarin with different doses $(75 \mathrm{mg} / \mathrm{kg} \cdot \mathrm{bw}$ and $150 \mathrm{mg} / \mathrm{kg} \cdot \mathrm{bw}$ ) via intragastric administration. Changes in organ indexes, pathological changes, liver-function index, biochemical indexes, molecular biological indexes, and genes related to the oxidation and inflammation of main organs were evaluated.

Results: After the mice were treated with silymarin, their body weight showed no significant change, and the liver, kidney, and lung indexes of the treated mice were higher than those of the model group; meanwhile, the corresponding histopathological formation was reduced. Compared with the model group, the silymarin-treated group showed reductions in ALT, AST, and liver function indexes in the mouse serum. Silymarin treatment also increased the SOD, CAT, GSH, GSH-Px, T-AOC, IL-10, and IL-12 levels, as well as reduced the MDA, NO, IL-6, IL-1 $\beta$, TNF- $\alpha$, IFN- $\gamma$ levels in the mouse serum and liver tissues. In addition, quantitative polymerase chain reaction analysis indicated that the mRNA expression levels of SOD1, SOD2, CAT, GSH-Px, IL-10, Nrf2, HO-1, NQO1, Trx , and I $K B-\alpha$ were higher in the liver tissue of the silymarin-treated mice than in those of the model group; meanwhile, the mRNA expression levels of $I L-6, I L-1 \beta, T N F-\alpha, I F N-\gamma, N F-\kappa B, N L R P 3, C O X 2$, and $p 38$ were lower than those in the model group.

Conclusion: Silymarin, which exhibits antioxidative and anti-inflammatory effects, can alleviate the liver, lung, and kidney damage induced by D-galactose/lipopolysaccharide. High-dose $(150 \mathrm{mg} / \mathrm{kg} \cdot \mathrm{bw})$ silymarin can more effectively inhibit organ damage, compared with low-dose silymarin $(75 \mathrm{mg} / \mathrm{kg} \cdot \mathrm{bw})$ in Kunming mice.

Keywords: silymarin, organ injury, D-galactose/lipopolysaccharide, antioxidation, antiinflammation

\section{Introduction}

Sepsis is a clinical syndrome, with infection as the pathological basis and inflammatory response as the basic pathological change. It can often cause damage to multiple systems and multiple organs and ultimately lead to multiple-organ failure. The course of inflammation in patients usually ranges from inflammatory reactions to sepsis, severe sepsis, septic shock, and multiple-organ failure. Owing to relatively weak immunity, infants and the elderly are more likely to induce sepsis and sepsis-related deaths than other patient groups. ${ }^{1}$ The mechanisms underlying sepsis and secondary organ injury (liver, lung, kidneys, and other important organs) leading to death and 
inflammation have yet to be determined. Liver injury can also induce and aggravate injury to other organs. The reason is that the liver has important functions, such as detoxification and immunity. Currently, the main mechanisms of sepsis-induced liver injury include microcirculation disturbance, energy metabolism disturbance of hepatocytes, dysfunction of hepatocytes and liver, effects of endotoxins, oxygen-free radicals, and lipid peroxidation. ${ }^{2-6}$ No effective clinical treatment has been developed for complications caused by sepsis, although the initial inflammation is widely regarded as the cause of organ damage. Therefore, sepsis should preferably be treated by regulating the immune inflammatory response.

A component of the external cell wall of Gram-negative bacteria, lipopolysaccharide (LPS) can induce a severe inflammatory response in organs, leading to severe systemic inflammatory response syndrome. Liver cells, including Kupffer cells, hepatocytes, and sinusoidal gland endothelial cells, can absorb LPS in the blood circulation after LPS injection in vivo. ${ }^{7}$ Excessive intake of D-galactose can lead to peroxidation of cells and tissues and the production of oxidation products. ${ }^{8}$ In addition, D-galactose can enhance the sensitivity of liver cells to LPS, as well as induce liver damage and an abnormal increase in serum TNF- $\alpha$ in a lowconcentration LPS environment. ${ }^{9}$

Silymarin is extracted from the seeds of Silybum marianum L. Gaertn (also known as milk thistle). ${ }^{10}$ Silymarin is a mixture containing various flavonoids, mainly including silybin, silydianin, silychristin, and other active ingredients. ${ }^{11}$ This mixture acts as an antioxidant, an antiinflammatory, and an anti-cancer; moreover, it protects the liver and lowers enzymes and lipids, particularly in the treatment of liver diseases. ${ }^{12,13}$

In the present study, we used LPS and D-Gal to induce organ damage caused by sepsis in mice to explore the function of silymarin in endotoxic organ damage, particularly liver damage, and further analyze its histological changes, oxidation and inflammatory factor levels, and the possible molecular mechanism of action.

\section{Materials and Methods}

\section{Chemicals}

We used a commercial silymarin product (item number: $\mathrm{S} 25549$, UV $\geq 80 \%$ ) rich in flavonoids, mainly including silybin, isosilybin, silydianin, and silychristin (structural formula is shown in Figure 1), among which silybin content is about $70 \%$, manufactured by Shanghai Yuanye Bio-
Technology Co., Ltd. (Shanghai, China). D-galactose (item number: IG0540) and LPS (item number: L8880, from Escherichia coli 055: B5) were supplied by Beijing Solarbio Science \& Technology Co., Ltd. (Beijing, China).

\section{Animals}

The experiment was conducted on male Kunming mice aged 6-8 weeks and weighing 35-40 g (Experimental Animal Center of Chongqing Medical University, Chongqing, China). The experimental mice were isolated and placed in an animal room at $20^{\circ} \mathrm{C}-25^{\circ} \mathrm{C}$ with $50 \%-$ $60 \%$ humidity, and the circadian rhythm was the standard. Animals were given free access to standard diet and water. They were kept in a standard laboratory cage for 1 week and were randomly divided into 4 groups of 10 animals each: the control group, the model group, the Silymarin-L group, and the Silymarin-H group.

\section{Experimental Treatment}

The mice in the control group were given distilled water by gavage daily and normal saline via intraperitoneal injection daily. The mice in the model group were also given distilled water by gavage daily and D-gal $(30 \mathrm{mg} /$ $\mathrm{kg} \cdot \mathrm{bw}) / \mathrm{LPS}(3 \mu \mathrm{g} / \mathrm{kg} \cdot \mathrm{bw})$ via intraperitoneal injection daily. In the silymarin-L group, D-Gal $(30 \mathrm{mg} / \mathrm{kg} \cdot \mathrm{BW}) /$ LPS ( $3 \mu \mathrm{g} / \mathrm{kg} \cdot \mathrm{bw})$ was given via intraperitoneal injection after intragastric administration of silymarin (75 mg/ $\mathrm{kg} \cdot \mathrm{bw})$ daily, while in the silymarin-H group, D-Gal $(30 \mathrm{mg} / \mathrm{kg} \cdot \mathrm{bw}) / \mathrm{LPS}(3 \mu \mathrm{g} / \mathrm{kg} \cdot \mathrm{bw})$ was given via intraperitoneal injection after intragastric administration of silymarin (150 $\mathrm{mg} / \mathrm{kg} \cdot \mathrm{bw})$ daily. ${ }^{14}$ The intragastric (or intraperitoneal) dose was $0.1 \mathrm{~mL} / 10 \mathrm{~g}$ of body weight. D-Gal and LPS were dissolved in normal saline and administered via intraperitoneal injection. Silymarin suspension was prepared with distilled water and administered via gavage. During the experiment (4 weeks), the four groups of experimental mice were given intragastric and intraperitoneal injections every day, and were given an equal and sufficient standard diet. After the experiment for 4 weeks, all mice underwent fasting for $18 \mathrm{~h}$ to eliminate some components in diet that may have an impact on the detection indicators during which period they were allowed to drink and move freely. Blood was collected from the retro orbital plexus of mice after ether anesthesia and then euthanized by cervical dissection. Liver, kidney, and lung tissues were obtained. Serum and tissues were stored at $-80{ }^{\circ} \mathrm{C}$ for subsequent experiments. This study was approved by the Ethics Committee of Chongqing 
Collaborative Innovation Center for Functional Food (202003050B, Chongqing, China) and adhered to the National Standards of the People's Republic of China (GB/T 35892-2018) laboratory animal guidelines for ethical review of animal welfare.

\section{Weight and Organ Index Assays}

During the treatment period, all mice were weighed weekly, and changes in body weight were recorded. After the mice were sacrificed, the liver, kidneys, and lungs were accurately weighed to determine the organ indexes.

\section{Histological Examination}

After sacrificing the mice, we also collected liver, lung, and kidney tissue samples for histological analysis. The samples were placed in a $10 \%$ formalin buffer solution for tissue fixation. They were then embedded in paraffin, sliced into $3 \mu \mathrm{m}$ sections, and stained with standard hematoxylin-eosin. A cross-sectional analysis was performed under a microscope (Olympus Tokyo, Japan).

\section{Biochemical Assays}

Mouse blood was centrifuged (4000 r/min, $10 \mathrm{~min}$ ) to obtain the upper serum. Indicators of serum liver function (alanine aminotransaminase (ALT, item number: C009-2-1) and aspartate aminotransaminase (AST, item number: C010-2-1)) and oxidation (superoxide dismutase (SOD, item number: A001-3-2), catalase (CAT, item number: A007-1-1), glutathione (GSH, item number: A006-2-1), glutathione peroxidase (GSH-Px, item number: A005-1-1), total antioxidant capacity (T-AOC, item number: A015-3-1), malondialdehyde (MDA, item number: A003-4-1), and nitric oxide (NO, item number: A013-2-1)) in mice were measured using the assay kit (Jiancheng Institute of Bioengineering, Nanjing City, Jiangsu Province, China). Factors related to inflammation (IL-1 $\beta$ (item number: ml063132), IL-6 (item number: ml063159), IL-10 (item number: ml037873), TNF- $\alpha$ (item number: ml002095), IFN- $\gamma$ (item number: ml002277), and IL-12 (item number: ml037868)) were measured using enzyme-linked immunosorbent assay kits (Shanghai Enzymelinked Biotechnology Co., Ltd., Shanghai City, China).

A liver homogenate was prepared from $1 \mathrm{~g}$ of homogenized liver tissue, with normal saline in the 1:9 ratio at 4 ${ }^{\circ} \mathrm{C}$. The previously mentioned oxidation-related indicators were determined using the kit (Jiancheng Institute of Bioengineering, Nanjing City, Jiangsu Province, China). The previously mentioned inflammation-related factors were determined using enzyme-linked immunosorbent assay kits (ABCAM, Cambridge, Massachusetts, USA).

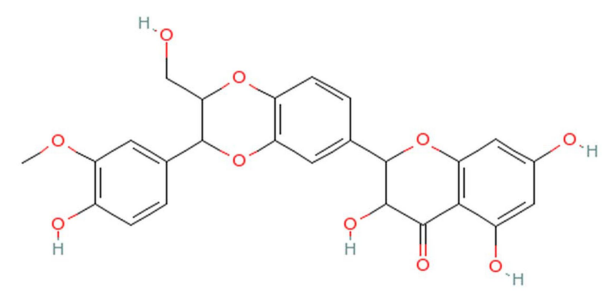

A Silybin

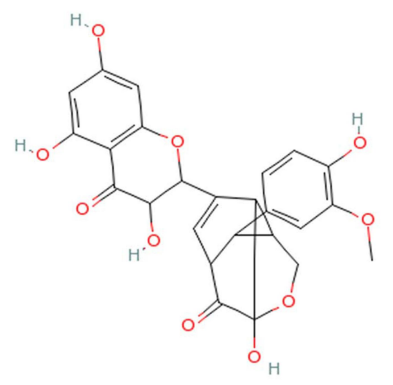

C Silydianin

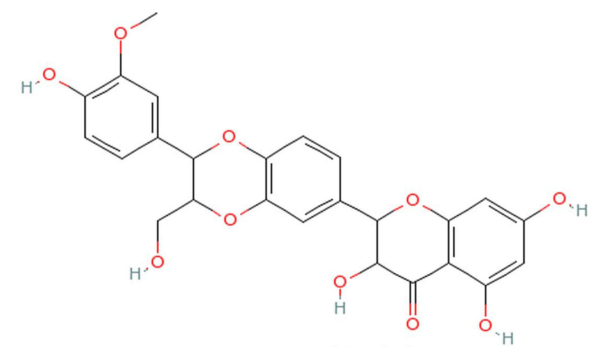

B Isosilybin

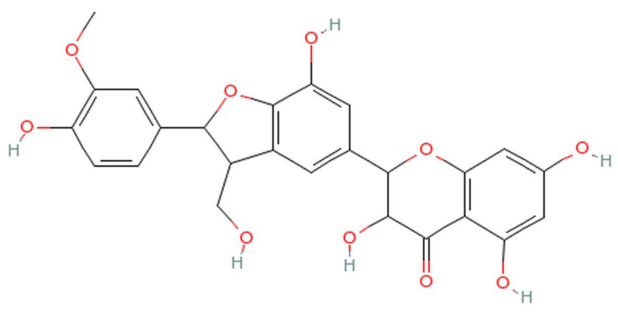

D Silychristin

Figure I Chemical structures of key components of silymarin in this study A: silybin; B: isosilybin; C: silydianin; D: silychristin. 


\section{Gene Assays (RT-qPCR Method)}

$\beta$-actin was selected as the internal reference for mRNA. Measurement was conducted as follows: Liver tissue was homogenized (Bioprep-24, Hangzhou Allsheng Instruments Co., Ltd., Hangzhou, China), lysed with the TRIzol reagent (Thermo Fisher Scientific, Inc., Waltham, MA, USA), extracted with chloroform, precipitated with isopropanol, washed with $75 \%$ ethanol, dissolved in water treated with diethyl pyrocarbonate (DEPC), and analyzed using a spectrophotometer to determine the level and purity of total RNA. According to the manufacturer's suggestion (RevertAid First Strand cDNA Synthesis Kit; Thermo Fisher Scientific, Inc., Waltham, MA, USA), $1 \mu \mathrm{L}$ oligo (dT) 18 primer (500 ng) and $1.0 \mu \mathrm{L}$ of RNA $(1.0 \mu \mathrm{g})$ were added to $10.0 \mu \mathrm{L}$ of nucleasefree water, and heated on a gradient PCR instrument at $65^{\circ} \mathrm{C}$ for 5 minutes. Then, the mixed reagent containing $4.0 \mu \mathrm{L}$ of $5 \times$ Reaction Buffer, $1.0 \mu \mathrm{L}$ of Ribolock RNase Inhibitor (20 U), $2.0 \mu \mathrm{L}$ of $10 \mathrm{mM}$ dNTP Mix and $1.0 \mu \mathrm{L}$ of ReverAid Reverse Transcriptase $(200 \mathrm{u} / \mu \mathrm{L})$ were added to the above total RNA system. The mixture was reverse transcribed into cDNA at $42^{\circ} \mathrm{C}$ for 60 minutes and $70^{\circ} \mathrm{C}$ for 5 minutes. The total reaction system $(20 \mu \mathrm{L})$ consisted of $1.0 \mu \mathrm{L}$ cDNA, $1.0 \mu \mathrm{L}$ each of forward and reverse primers $(10 \mu \mathrm{M}), 10.0 \mu \mathrm{L}$ premix $\left(\right.$ SYBR $^{\circledR}$ Select Master Mix; Thermo Fisher Scientific, Inc., Waltham, MA, USA), and $7.0 \mu \mathrm{L}$ sterilized double-steamed water; it was mixed and reacted on an automatic thermal cycler (SteponePlus, Thermo Fisher Scientific, Inc., Waltham, MA, USA). The amplification conditions were as follows: denatured at $95{ }^{\circ} \mathrm{C}$ for $3 \mathrm{~min}$, annealed at $60{ }^{\circ} \mathrm{C}$ for $30 \mathrm{~s}$, and extended at $95{ }^{\circ} \mathrm{C}$ for $1 \mathrm{~min}$ and cycled 40 times. Gene expression was calculated using the $2^{-\Delta \Delta C T}$ method. ${ }^{15}$ The primer sequences are listed in Table 1.

\section{Statistical Analysis}

The significant difference between groups was evaluated using SPSS ver. 20.0 (SPSS Inc., Chicago, Illinois, USA). The Shapiro-Wilk test and Quantile-Quantile Plot were used to test the data normality, and one-way ANOVA and Tukey's test were used for analysis significance. The experiment was repeated three times. The results are expressed as mean \pm standard deviation, and $p<0.05$ was considered statistically significant.

\section{Results}

Changes in Body Weight and Organ Index Table 2 shows the weight change of mice in each group during the experiment, and the weight change is not significant
Table I Primer Sequences in This Study

\begin{tabular}{|c|c|}
\hline Gene Name & Sequence \\
\hline SODI & $\begin{array}{l}\text { Forward: 5'-AACCAGTTGTGTTGTGAGGAC-3' } \\
\text { Reverse: 5'-CCACCATGTTTCTTAGAGTGAGG-3' }\end{array}$ \\
\hline SOD2 & $\begin{array}{l}\text { Forward: 5'-CAGACCTGCCTTACGACTATGG-3' } \\
\text { Reverse: 5'-CTCGGTGGCGTTGAGATTGTT-3' }\end{array}$ \\
\hline CAT & $\begin{array}{l}\text { Forward: 5'-GGAGGCGGGAACCCAATAG-3' } \\
\text { Reverse: 5'-GTGTGCCATCTCGTCAGTGAA-3' }\end{array}$ \\
\hline GSH-Px & $\begin{array}{l}\text { Forward: 5'-GTCGGTGTATGCCTTCTCGG-3' } \\
\text { Reverse: 5'-AGAGAGACGCGACATTCTCAAT-3' }\end{array}$ \\
\hline IL-10 & $\begin{array}{l}\text { Forward: 5'-CTTACTGACTGGCATGAGGATCA-3' } \\
\text { Reverse: 5'-GCAGCTCTAGGAGCATGTGG-3' }\end{array}$ \\
\hline IL-6 & $\begin{array}{l}\text { Forward: 5'-CTGCAAGAGACTTCCATCCAG-3' } \\
\text { Reverse: 5'-AGTGGTATAGACAGGTCTGTTGG-3' }\end{array}$ \\
\hline TNF- $\alpha$ & $\begin{array}{l}\text { Forward: 5'-CAGGCGGTGCCTATGTCTC-3' } \\
\text { Reverse: 5'-CGATCACCCCGAAGTTCAGTAG-3' }\end{array}$ \\
\hline IFN- $\gamma$ & $\begin{array}{l}\text { Forward: 5'-GGCCTAGCTCTGAGACAATGAAC-3' } \\
\text { Reverse: 5'-TGACCTCAAACTTGGCAATACTC-3' }\end{array}$ \\
\hline IL-I $\beta$ & $\begin{array}{l}\text { Forward: 5'-GAAATGCCACCTTTTGACAGTG-3' } \\
\text { Reverse: 5'-TGGATGCTCTCATCAGGACAG-3' }\end{array}$ \\
\hline Nrf2 & $\begin{array}{l}\text { Forward: 5'-TAGATGACCATGAGTCGCTTGC-3' } \\
\text { Reverse: 5'-GCCAAACTTGCTCCATGTCC-3' }\end{array}$ \\
\hline $\mathrm{HO}-\mathrm{I}$ & $\begin{array}{l}\text { Forward: 5'-GATAGAGCGCAACAAGCAGAA-3' } \\
\text { Reverse: 5'-CAGTGAGGCCCATACCAGAAG-3' }\end{array}$ \\
\hline NQOI & $\begin{array}{l}\text { Forward: 5'-AGGATGGGAGGTACTCGAATC-3' } \\
\text { Reverse: 5'-TGCTAGAGATGACTCGGAAGG-3' }\end{array}$ \\
\hline $\operatorname{Trx}$ & $\begin{array}{l}\text { Forward: 5'-TGCTACGTGGTGTGGACCTTGC-3' } \\
\text { Reverse: 5'-ACCGGAGAACTCCCCCACCT-3' }\end{array}$ \\
\hline NF- $\kappa B$ & $\begin{array}{l}\text { Forward: 5'-ATGGCAGACGATGATCCCTAC-3' } \\
\text { Reverse: 5'-CGGAATCGAAATCCCCTCTGTT-3' }\end{array}$ \\
\hline IKB- $\alpha$ & $\begin{array}{l}\text { Forward: 5'-CGCGGGATGGCCTCAAGAAGGA-3' } \\
\text { Reverse: 5'-GCCAAGTGCAGGAACGAGTCT-3' }\end{array}$ \\
\hline NLRP3 & $\begin{array}{l}\text { Forward: 5'-ATTACCCGCCCGAGAAAGG-3' } \\
\text { Reverse: 5'-CATGAGTGTGGCTAGATCCAAG-3' }\end{array}$ \\
\hline $\operatorname{cox} 2$ & $\begin{array}{l}\text { Forward: 5'-TTCCAATCCATGTCAAAACCGT-3' } \\
\text { Reverse: 5'-AGTCCGGGTACAGTCACACTT-3' }\end{array}$ \\
\hline p38 & $\begin{array}{l}\text { Forward: 5'-CTGACCGACGACCACGTTC-3' } \\
\text { Reverse: 5'-CTTCGTTCACAGCTAGGTTGC-3' }\end{array}$ \\
\hline$\beta$-Actin & $\begin{array}{l}\text { Forward: 5'-GAGAAAATCTGGCACCACACCT-3' } \\
\text { Reverse: 5'- GCACAGCCTGGATAGCAACGTA-3' }\end{array}$ \\
\hline
\end{tabular}

$(p>0.05)$. After the experiment, increases in body weight were observed: $24.24 \%$ in the control group, $20.94 \%$ in the model group, and $23.71 \%$ in the silymarin- $\mathrm{H}$ group. 
Table 2 Changes in Body Mass in Mice. (N=10/Group)

\begin{tabular}{|l|l|l|l|l|}
\hline Weeks and Weight Change Rate & Normal & Model & Silymarin-L & Silymarin-H \\
\hline Week $0(\mathrm{~g})$ & $38.48 \pm 2.54^{\mathrm{A}}$ & $37.96 \pm 1.41$ & $37.97 \pm 1.19$ & $38.64 \pm 2.28$ \\
\hline Week I (g) & $41.86 \pm 3.40$ & $40.48 \pm 2.25$ & $40.91 \pm 1.4$ & $41.52 \pm 3.42$ \\
\hline Week 2 (g) & $44.12 \pm 3.58$ & $43.40 \pm 3.24$ & $42.27 \pm 1.27$ & $44.69 \pm 4.18$ \\
\hline Week 3 (g) & $46.26 \pm 3.47$ & $44.66 \pm 2.91$ & $44.82 \pm 2.44$ & $45.99 \pm 4.72$ \\
\hline Week $4(\mathrm{~g})$ & $47.81 \pm 3.33$ & $45.91 \pm 3.46$ & $45.96 \pm 2.66$ & $47.8 \pm 4.1$ \\
\hline Rate $(\%)$ & 24.24 & 20.94 & 21.04 & 23.71 \\
\hline
\end{tabular}

Notes: Model, treated with D-Gal/LPS $(250 \mathrm{mg} / \mathrm{kg}$ bw and $25 \mathrm{mg} / \mathrm{kg}$ bw) injection; silymarin-L: treated with silymarin $(75 \mathrm{mg} / \mathrm{kg} \cdot \mathrm{bw})$ oral administration; silymarin-H: treated with silymarin $\left(150 \mathrm{mg} / \mathrm{kg}\right.$ bw) oral administration. ${ }^{A}$ Values presented are the mean \pm standard deviation (SD) of different organ coefficients. Rate $(\%)=($ mice weight in week 4 - mice weight in week 0$) /$ mice weight in week $0 \times 100 \%$.

As shown in Table 3, the largest decrease in organ index was observed in the model group treated with D-Gal/LPS. On the contrary, the organ index of silymarin group increased, but with high-dose silymarin, a significant difference was determined $(p<0.05)$. The experiment confirmed that treatment with silymarin can prevent organ atrophy caused by D-Gal/LPS.

\section{Evaluation of Histological Changes}

As shown in Figure 2, control mouse liver cells with clear structures are neatly arranged; hepatocyte cords are systematically arranged and distributed in a radial pattern. In the model group, the liver cell structure was damaged, poorly arranged, and characterized by indistinct boundaries, inflammatory cell infiltration, and liver cell necrosis. Liver cell damage in mice was reduced in the silymarin group; specifically, the arrangement and structural integrity of hepatocytes treated with silymarin-H were close to

Table 3 Effects of Silymarin on Organ Index of Liver, Lung and Kidney in Mice Induced by D-Gal/LPS ( $N=10 / G r o u p)$

\begin{tabular}{|l|l|l|l|}
\hline Groups & Liver Index & Lung Index & Kidney Index \\
\hline Normal & $42.15 \pm 1.5^{\mathrm{aA}}$ & $5.34 \pm 0.18^{\mathrm{b}}$ & $13.96 \pm 0.55^{\mathrm{b}}$ \\
\hline Model & $34.10 \pm 2.63^{\mathrm{c}}$ & $4.43 \pm 0.28^{\mathrm{c}}$ & $11.26 \pm 0.49^{\mathrm{d}}$ \\
\hline Silymarin-L & $36.76 \pm 0.87^{\mathrm{c}}$ & $5.32 \pm 0.17^{\mathrm{b}}$ & $12.52 \pm 0.29^{\mathrm{c}}$ \\
\hline Silymarin-H & $38.78 \pm 1.3^{\mathrm{b}}$ & $6.08 \pm 0.26^{\mathrm{a}}$ & $14.84 \pm 1.07^{\mathrm{a}}$ \\
\hline
\end{tabular}

Notes: Model, treated with D-Gal/LPS ( $250 \mathrm{mg} / \mathrm{kg}$ bw and $25 \mathrm{mg} / \mathrm{kg}$ bw) injection; silymarin-L: treated with silymarin $(75 \mathrm{mg} / \mathrm{kg}$ bw) oral administration; silymarin-H: treated with silymarin $\left(150 \mathrm{mg} / \mathrm{kg}\right.$ bw) oral administration. ${ }^{\mathrm{a}-\mathrm{d}}$ There was significant difference in different letters in the same column $(P<0.05)$, which was determined by Duncan's multiple range test. ${ }^{A} V$ alues presented are the mean \pm standard deviation $(\mathrm{SD})$ of different organ coefficients. Organ index $(\mathrm{mg} / \mathrm{g})=$ organ weight $(\mathrm{mg}) /$ body weight $(\mathrm{g})$. those of hepatocytes in the control group. Liver tissue cells treated with silymarin-L improved, with a small amount of inflammatory cell infiltration. Therefore, treatment with silymarin-H can effectively prevent liver damage in mice.

As shown in Figure 3, in the control group, the structure of lung tissue cells shows no irregularity, the alveolar cavity is clear, the alveolar wall is intact, and no apparent edema occurs in the alveoli and lung interstitium. In the model group, the cells are characterized by damage to the alveolar structure, alveolar wall edema, lung interstitial thickening, alveolar cavity atrophy, and inflammation injury. Relative to the model group, the silymarin groups exhibited reduced lung tissue edema and improved morphology. Notably, the alveoli and interstitia of mice in the silymarin-H group showed less edema and inflammation than of those in the silymarin- $\mathrm{L}$ group. Therefore, treatment with silymarin- $\mathrm{H}$ can more effectively alleviate lung injury in mice.

As shown in Figure 4, glomeruli and tubules have regular shapes, neatly arranged cells, and clear structures. In the model group, glomerular atrophy, endothelial cell swelling, shedding, and necrosis accompanied by interstitial edema and inflammatory cell infiltration were observed. Relative to those in the model group, the structure and morphology of kidney tissue in the silymarin treatment groups were repaired, and inflammatory cell infiltration was reduced to varying degrees; moreover, silymarin- $\mathrm{H}$ exerted a better effect than silymarin-L. Therefore, silymarin- $\mathrm{H}$ can effectively improve kidney damage in mice.

\section{AST and ALT Levels in Serum}

The AST and ALT activities of mice in the model group increased significantly by $66.42 \%(p<0.05)$ and $77.21 \%$ $(p<0.05)$, respectively (Table 4). Meanwhile, AST and ALT 

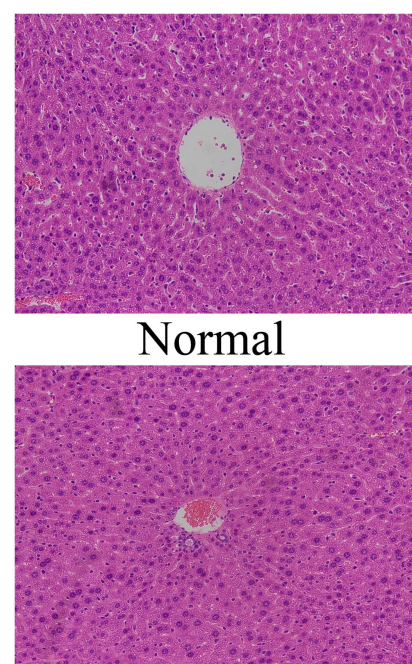

Silymarin-L

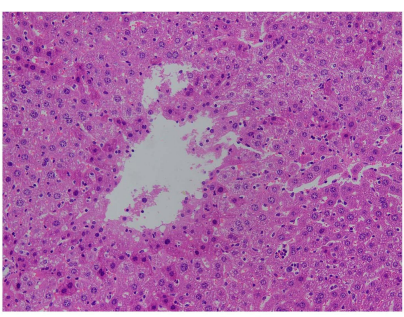

Model

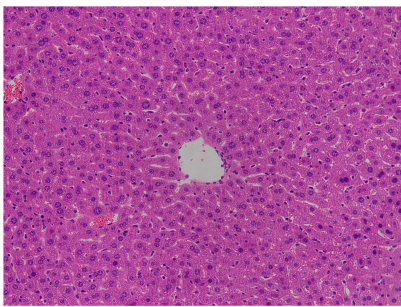

Silymairn-H

Figure 2 H\&E pathological staining structure of liver tissues. Model: treated with D-Gal/LPS (30 mg/kg bw/3 $\mu \mathrm{g} / \mathrm{kg}$ bw) intraperitoneal injection; silymarin-L: treated with silymarin $(75 \mathrm{mg} / \mathrm{kg} \cdot \mathrm{bw})$ intragastric administration; silymarin- $\mathrm{H}$ : treated with silymarin (150 mg/kg bw) intragastric administration.

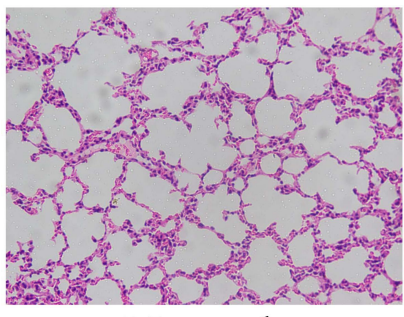

Normal

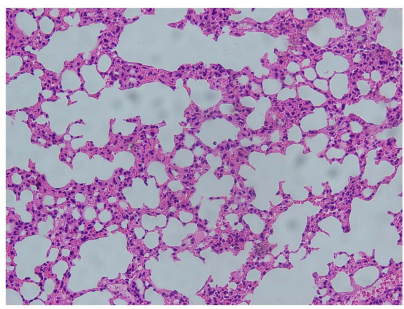

Silymarin-L

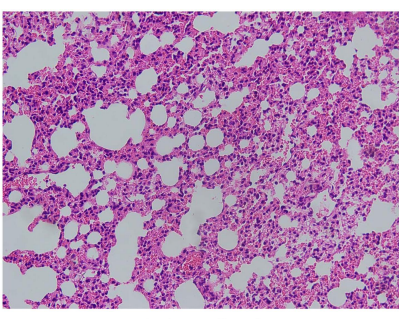

Model

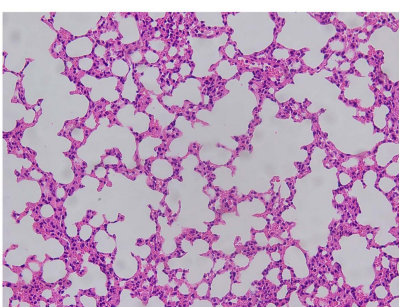

Silymarin-H

Figure $3 \mathrm{H} \& \mathrm{E}$ pathological staining structure of lung tissues. Model: treated with D-Gal/LPS (30 mg/kg bw/3 $\mu \mathrm{g} / \mathrm{kg}$ bw) intraperitoneal injection; silymarin-L: treated with silymarin $(75 \mathrm{mg} / \mathrm{kg} \cdot \mathrm{bw})$ intragastric administration; silymarin-H: treated with silymarin ( $150 \mathrm{mg} / \mathrm{kg}$ bw) intragastric administration.

in the silymarin groups decreased to varying degrees, suggesting that silymarin exerts a certain protective effect on the liver of the mice.

SOD, CAT, GSH, GSH-Px, T-AOC, MDA, and NO Levels in Serum and Liver Tissue

After D-Gal/LPS induction, the serum (or liver tissue) SOD, CAT, GSH, GSH-Px and T-AOC levels of the model group

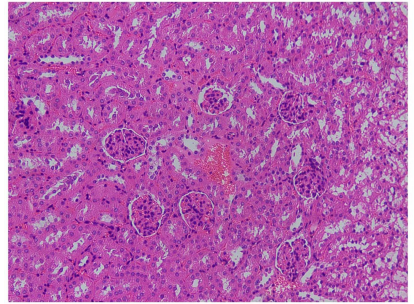

Normal

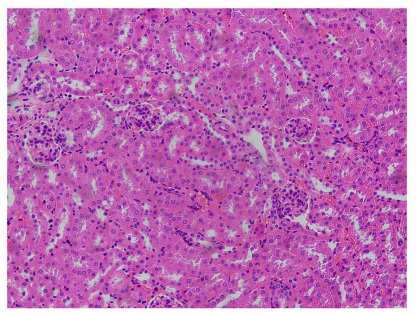

Silymarin-L

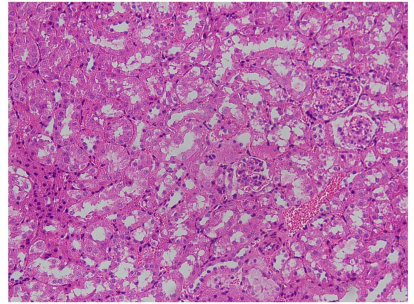

Model

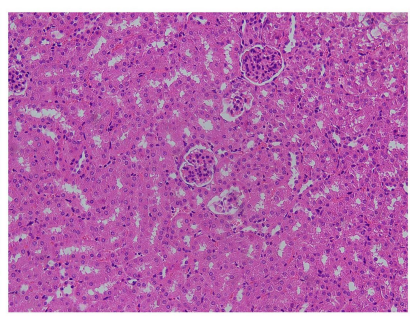

Silymarin-H
Figure $4 \mathrm{H} \& \mathrm{E}$ pathological staining structure of kidney tissues. Model: treated with D-Gal/LPS (30 mg/kg bw/3 $\mu \mathrm{g} / \mathrm{kg} \cdot \mathrm{bw})$ intraperitoneal injection; silymarin-L: treated with silymarin $(75 \mathrm{mg} / \mathrm{kg}$ bw) intragastric administration; silymarin- $\mathrm{H}$ : treated with silymarin $(150 \mathrm{mg} / \mathrm{kg}$ bw) intragastric administration.

mice were significantly lower than the other three groups, while the MDA and NO levels were significantly higher than the other three groups ( $p<0.05$, Table 5). The SOD, CAT, GSH-Px, GSH, and T-AOC serum levels were higher in the silymarin group than in the model group. Moreover, the effect of the silymarin- $\mathrm{H}$ group was better than that of silymarin-L. The MDA and NO levels showed opposite trends $(p<0.05)$. Treatment with silymarin-H can more effectively increase the SOD, CAT, GSH-Px, GSH, and T-AOC serum levels in mice and inhibit the MDA and NO levels.

\section{IL-6, IL-I0, IL-I 2, IL-I $\beta$, TNF- $\alpha$, and IFN- $\gamma$ Levels in Serum and Liver Tissue}

The serum (or liver) levels of IL-6, IL-1 $\beta$, TNF- $\alpha$, and IFN- $\gamma$ in the model group were significantly higher,

Table 4 Serum Levels of AST and ALT in Mice ( $N=10 /$ Group)

\begin{tabular}{|l|l|l|}
\hline Groups & AST (U/L) & ALT (U/L) \\
\hline Normal & $8.40 \pm 0.72^{\mathrm{cA}}$ & $8.69 \pm 3.62^{\mathrm{b}}$ \\
\hline Model & $13.98 \pm 0.39^{\mathrm{a}}$ & $15.4 \pm 0.99^{\mathrm{a}}$ \\
\hline Silymarin-L & $10.87 \pm 1.38^{\mathrm{b}}$ & $13.76 \pm 1.96^{\mathrm{a}}$ \\
\hline Silymarin-H & $8.8 \pm 1.26^{\mathrm{c}}$ & $8.52 \pm 1.35^{\mathrm{b}}$ \\
\hline
\end{tabular}

Notes: Model, treated with D-Gal/LPS ( $250 \mathrm{mg} / \mathrm{kg}$ bw and $25 \mathrm{mg} / \mathrm{kg}$ bw) injection; silymarin-L: treated with silymarin $(75 \mathrm{mg} / \mathrm{kg}$ bw) oral administration; silymarin-H: treated with silymarin $\left(150 \mathrm{mg} / \mathrm{kg}\right.$ bw) oral administration. ${ }^{a-c}$ There was significant difference in different letters in the same column $(P<0.05)$, which was determined by Duncan's multiple range test. AValues presented are the mean \pm standard deviation (SD) of different organ coefficients. 


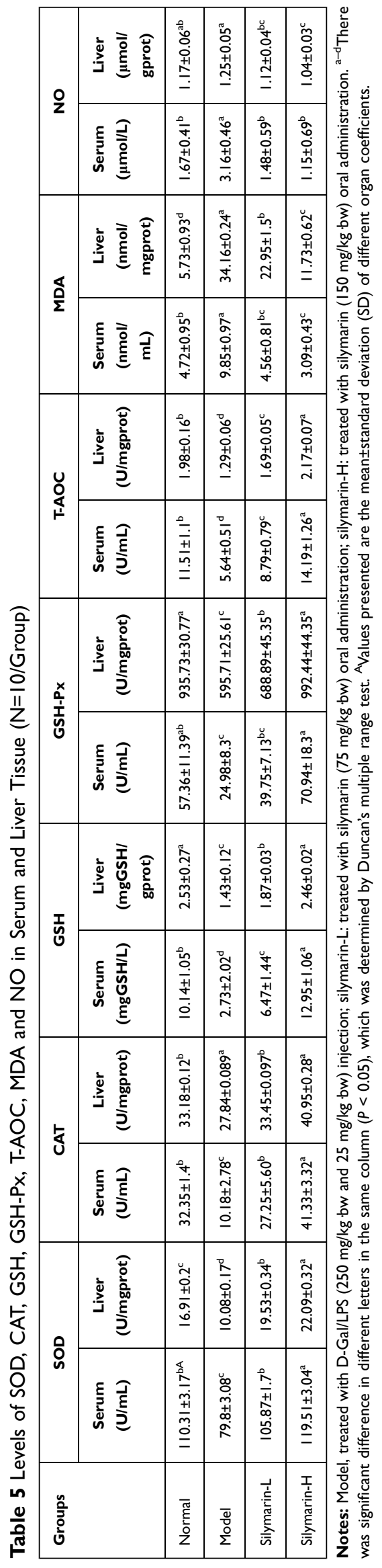

while the levels of IL-10 and IL-12 levels were significantly lower than the other three groups $(p<0.05$, Table 6). Treatment with silymarin can significantly reduce the serum (or liver) levels of IL-6, IL-1 $\beta$, TNF- $\alpha$ and IFN- $\gamma$ and increase the those of IL-10 and IL-12 $(p<0.05)$. Moreover, the regulating effect of silymarin-H on cytokines is better than that of silymarin-L group.

\section{Expression of mRNA Related to Oxidative Stress and Inflammation in Liver Tissues}

The mice in the model group showed the lowest expression levels of SOD1, SOD2, CAT, and GSH-PX mRNA in liver tissues (Figure 5A). The mRNA expression levels of $S O D 1, S O D 2, C A T$, and GSH-Px were significantly increased in the silymarin- $\mathrm{H}$ group relative to those in the model group $(p<0.05)$, which were close to those in the control group; meanwhile, silymarin-L exerted a weaker effect than that of silymarin-H.

As shown in Figure 5B, the mice in the model group show the lowest mRNA expression of $I L-6, I L-1 \beta, T N F-\alpha$, and $I F N-\gamma$ and the mRNA expression of $I L-10$ in the liver tissue. After treatment with silymarin, the mice showed decreased expression of $I L-6, I L-1 \beta, T N F-\alpha$ and $I F N-\gamma$ mRNA in the liver and and increased mRNA expression of $I L-10$. And the therapeutic effect of silymarin-H group was better than silymarin-L group.

As shown in Figure 5C, the mRNA expression levels of Nrf2, HO-1, NQO-1, and Trx in the model mice were significantly lower than those in the control group. Treatment with silymarin-L increased the mRNA expression of Nrf2, HO-1, NQO-1, and Trx. Specifically, the mRNA expression levels of $N r f 2, H O-1, N Q O-1$, and Trx in the liver tissue of the silymarin- $\mathrm{H}$ group were higher than those in silymarin-L group.

As shown in Figure 5D, the mRNA expression levels of $N F-\kappa B, N L R P 3, C O X 2$, and $p 38$ in the lives of the mice in the model group are higher than those of the other groups, whereas the mRNA expression of I $\kappa-\alpha$ shows the opposite trend. Relative to those of the mice in the model group, the $N F-\kappa B, N L R P 3, C O X 2$, and $p 38$ mRNA expression levels were decreased, whereas the mRNA expression of $I \kappa B-\alpha$ was increased after silymarin treatment, and the high-dose silymarin effect was better. 


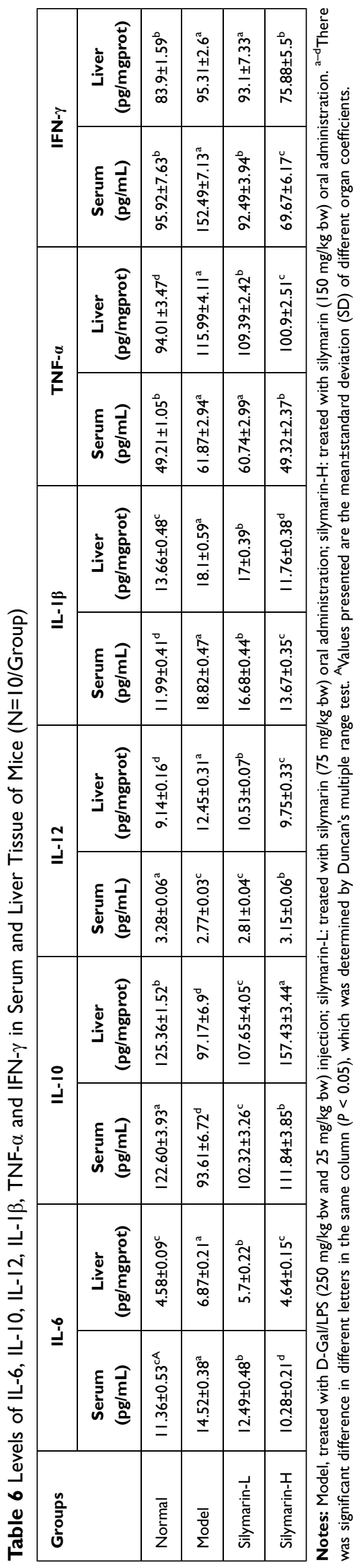

\section{Discussion}

Sepsis refers to the systemic inflammatory response syndrome caused by infection. Bacterial endotoxin has been shown to possess the ability to induce sepsis. Uncontrolled inflammatory response, immune disorder, hypermetabolism, and multi-organ dysfunction in the pathophysiological process of sepsis can be directly or indirectly triggered by endotoxin. ${ }^{16}$ As one of the main components of the cell wall of pathogenic bacteria, LPS is released during the growth, reproduction, death, rupture or dissolution of bacteria, prompting the release of multiple-organ damage and inflammation. Long-term incomplete metabolism of D-Gal can cause oxidative stress in the body, triggering inflammation. Simultaneously, D-Gal can increase the sensitivity of LPS and increase the lethality of mice. However, the mechanism of D-Gal/LPS inducing systemic inflammation has yet to be elucidated. ${ }^{17}$ Thus, intraperitoneal injection of D-Gal/LPS was used in the current study to construct a mouse model of systemic inflammation, and found that D-Gal/LPS can induce liver, lung, and kidney tissue lesions in mice, and oxidative stress and inflammation appeared, indicating that the model was successfully prepared.

Silymarin refers to a class of flavonolignans analogue compound formed by condensation of dihydroflavonols and phenylpropanin derivatives extracted from the milk thistle, originally native to the Mediterranean region, which can inhibit organ damage caused by D-Gal, alcohols, and other toxins. ${ }^{18,19}$ Silymarin can protect liver cell membranes by inhibiting NO production and anti-glutathione emptying and antilipid peroxidation, as well as removing ROS from the body, synthesizing structural proteins and DNA, and repairing damaged liver cells. $^{20-22}$ Silymarin also exerts antifibrotic and antitumor, anti-inflammatory, and pharmacological effects in the treatment of diabetes. ${ }^{23-25}$ The main active ingredient of "silymarin" is silybin. ${ }^{26}$ Silymarin can reduce lactate dehydrogenase, NO, and ROS levels, as well as maintain redox balance. ${ }^{27}$ It can also inhibit the mitochondrial apoptosis pathway by maintaining the integrity of the mitochondrial function. ${ }^{28,29}$

This study found that excessive intake of D-Gal/LPS can lead to physiologic metabolic disorders in mice, thereby influencing weight gain. Moreover, the liver, kidney, and lung organ coefficients of mice with D-Gal/LPS injury were lower than those of mice in the control group. Silymarin can significantly increase liver, kidney, and lung coefficients, improve liver, lung, and kidney tissue lesions, 

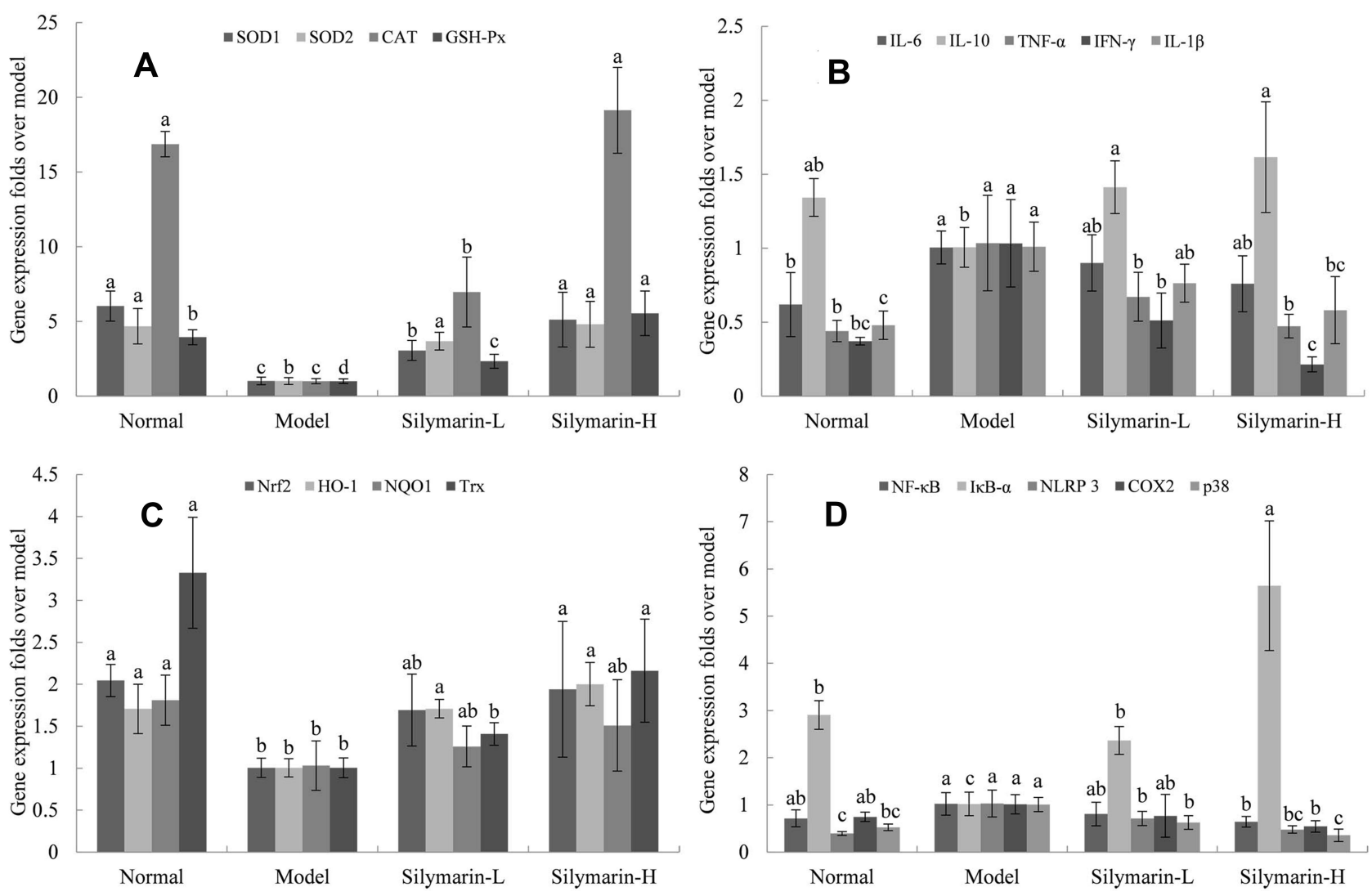

Figure 5 mRNA expression in mice liver tissue with D-Gal/LPS-induced organ injury. (A) SODI, SOD2, CAT and GSH-Px; (B) IL-6, IL-I0, IL-I $\beta$, TNF- $\alpha$ and IFN- $\gamma$; (C) Nrf2, HO-I, NQOI and Trx; (D) NF- KB, I $\mathrm{kB} \alpha$, NLRP3, COX2 and p38. Model: treated with D-Gal/LPS (30 mg/kg bw/3 $\mu \mathrm{g} / \mathrm{kg} \cdot \mathrm{bw})$ intraperitoneal injection; silymarin-L: treated with silymarin $\left(75 \mathrm{mg} / \mathrm{kg}\right.$ bw) intragastric administration; silymarin-H: treated with silymarin ( $150 \mathrm{mg} / \mathrm{kg}$ bw) intragastric administration. ${ }^{\mathrm{a}-\mathrm{d}}$ Mean values with different letters in the same column are significantly different $(p<0.05)$ according to Tukey's test.

and reduce inflammatory cell infiltration. The finding indicates that a certain amount of silymarin in the human body can protect the liver, kidney, and lung systems from D-Gal/LPS damage; repair their tissue cells; and maintain the normal metabolic function of the tissue.

When the body is in a state of oxidative stress, the liver cells change, and cell membrane permeability increases, causing ALT and AST in the cytoplasm to leak into the blood. The ALT and AST in the blood increase significantly, and the degree of increase is positively correlated with the degree of liver damage. ${ }^{30}$ Research by Hajiaghamohammadi et al showed that patients with nonalcoholic fatty liver disease after silymarin treatment had a significant decrease in serum AST and ALT. $^{24}$ The results of this experiment showed that compared with D-Gal/LPS-injured mice, after the intervention of silymarin, the contents of ALT and AST in the mouse serum were significantly reduced, and the degree of liver damage was reduced, suggesting that silymarin can improve liver function in mice with liver injury.
Excess free radicals induced by D-Gal/LPS can oxidize liver cell proteins, DNA, and cell membranes to form MDA, an end product of lipid peroxidation. Combined MDA and free radicals damage biological membranes and induce liver damage. ${ }^{31} \mathrm{NO}$ is a potentiating factor with cytotoxicity, which plays an amplifying role in lipid peroxidation and aggravates liver damage and pathology. ${ }^{32}$ SOD, GSH-Px, and CAT in the body are endogenous antioxidants, which can scavenge free radicals in the body, resist oxidative stress induced by D-Gal/LPS, and protect damaged liver. ${ }^{33}$ Research by Kiruthiga et al found that silymarin can improve oxidative stress damage caused by benzo(a)pyrene and exogenous reactive oxygen species $\left(\mathrm{H}_{2} \mathrm{O}_{2}\right)$, and enhance lipid peroxidation scavenging ability and antioxidant defense ability. ${ }^{21}$ The results of this experiment show that silymarin can exert an antilipid peroxidation effect by improving liver tissue SOD and GSH-Px activities. The mechanism may be the promotion of cysteine by flavonoids to participate in GSH synthesis and inhibit calcium overload in mitochondria. Moreover, 
the levels of MDA and NO in the serum and liver of mice in the silymarin antagonist groups were reduced, indicating that this silymarin exerted antilipid peroxidation and free-radical-scavenging effects. The mechanism may be the binding of the amino group in the flavonoid molecule to the oxidant to prevent oxidative stress, reducing MDA and NO production.

After injury, liver can produce a large amount of proinflammatory cytokines such as IL- $1 \beta$, IL- 6 , TNF- $\alpha$, and IFN- $\gamma$, causing inflammation. In addition, the upregulation of the expression of pro-inflammatory cytokines can further promote the infiltration of lymphocytes, macrophages, and neutrophils into damaged organs and tissues, aggravate the inflammatory response, and form a vicious circle. ${ }^{34}$ Research by Kim et al showed that restraint stress can significantly increase the mRNA expression of TNF- $\alpha$, IL-1 $\beta$, and IL-6 in mice, whereas silymarin treatment clearly reversed the restraint stress-induced increase in the expression of these genes in the liver. ${ }^{22}$ The present study found that silymarin may reduce the inflammatory cytokines (IL-1 $\beta$, IL-6, TNF- $\alpha$, and IFN- $\gamma$ ) in the serum and liver and increase the level of anti-inflammatory (IL10 and IL-12) factors, exhibiting a positive antiinflammatory effect.

$\mathrm{NF}-\kappa \mathrm{B}$ is a transcription factor that participates in the regulation of gene expression during an inflammatory response. Excessive activation of NF- $\mathrm{\kappa B}$ signaling pathway plays an important role in the occurrence of tissue damage. ${ }^{35} \mathrm{NF}-\kappa \mathrm{B}$ is generally inhibited by $\mathrm{I \kappa B}-\alpha$ and exists in the cytoplasm in an inactive state. After I $\mathrm{B} B-\alpha$ phosphorylation is activated under external stimuli, the inhibitory effect of NF- $\mathrm{KB}$ is relieved and enters the nucleus after phosphorylation to promote the transcription of target genes. ${ }^{36}$ Members of the mitogen-activated protein kinase (MAPK) family mainly include p38 kinases, extracellular signal-regulated kinases, and c-Jun n-terminal kinases, which participate in various inflammatory reactions in the body. After the MAPK signaling pathway is activated, it can promote the release of numerous inflammatory factors in the body, aggravating the inflammatory response. $^{37}$ Cyclooxygenase-2 (COX-2) is an inducible enzyme less expressed in normal tissues and expressed when cells are induced by intracellular and extracellular stimuli, such as LPS, tumor necrosis factor, interleukin (IL)-1 $\beta$, and so on. ${ }^{38}$ The results of the present study showed that the NF- $\mathrm{KB}$ and $\mathrm{p} 38$ gene expression in the model group was significantly higher than that in the control group, suggesting that D-Gal/LPS-induced mice may activate the NF- $\mathrm{KB}$ and MAPK signaling pathway and cause inflammatory damage. After the mice were treated with silymarin, NF- $\mathrm{kB}$ and p38 inflammatory factors in the liver tissue were downregulated, and IкB- $\alpha$ gene expression was increased, indicating that silymarin can inhibit the inflammatory response, thereby alleviating liver damage. In addition, the gene expression level of COX-2 in the liver tissue was significantly reduced after silymarin treatment, increasing their anti-inflammatory activity.

Studies have shown that silymarin reduces LPS-induced acute lung injury by inhibiting the NLRP3 signaling pathway and can regulate thioredoxin (Trx), thus inhibiting the activation of NLRP3 inflammasomes to reduce macrophage toxicity induced by paraquat. ${ }^{39,40}$ However, the mechanism of silymarin in the treatment of multiple-organ damage induced by D-Gal/LPS requires further research. Nrf2 is an important transcription factor that regulates cellular oxidative stress response. By inducing and regulating the expression of antioxidant proteins, it reduces the damage caused by ROS and electrophilicity to cells, as well as maintains cell stability and dynamic redox balance. Both the stress protein HO- 1 and the flavinase NQO1 play a role in anti-oxidation and antiinflammation. ${ }^{41,42}$ The results of this experiment suggest that silymarin can enhance the anti-oxidation of Nrf2, HO-1, NQO1 and Trx in the liver and inhibit the NLRP3 inflammasome to protect the liver.

\section{Conclusions}

Silymarin can reduce D-Gal/LPS-induced organ damage in Kunming mice, and this effect is positively correlated with concentration. It can increase organ indexes, inhibit tissue pathological changes, and regulate oxidative stress and inflammation in mice by increasing antioxidant activity and content, reducing peroxide production, increasing the level of immune regulatory factors, and inhibiting the release of pro-inflammatory factors. Moreover, its mechanism of action may be related to the activation of the Nrf2/HO-1 signaling pathway and inhibition of the NF- $\mathrm{KB} / \mathrm{NLRP} 3$ signaling pathway.

\section{Acknowledgments}

This research was funded by the Chongqing University Innovation Research Group Project (CXQTP20033) and Scientific and Technological Innovation Project of "Construction of Double City Economic Circle in Chengdu-Chongqing Area" of Chongqing Education Commission (KJCX2020052), China. 


\section{Disclosure}

The authors declare no conflicts of interest in this work.

\section{References}

1. Eling TE, Baek SJ, Shim M, et al. NSAID activated gene (NAG-1), a modulator of tumorigenesis. J Biochem Mol Biol. 2006;39 (6):649-655. doi:10.5483/BMBRep.2006.39.6.649

2. Breit SN, Johnen H, Cook AD, et al. The TGF-p superfamily cytokine, MIC-1/GDF15: a pleotrophic cytokine with roles in inflammation, cancer and metabolism. Growth Factors. 2011;29(5):187-195. doi:10.3109/08977194.2011.607137

3. Crre J, Hebraud B, Bourin P. Concise review: growth differentiation factor 15 in pathology: a clinical role. Stem Cells Transl Med. 2013;2 (12):946-952. doi:10.5966/sctm.2013-0055

4. Soueek K, Slabakova E, Ovesna P, et al. Growth/differentiation factor-15 is anabundant cytokine in human seminal plasma. Hum Reprod. 2010;25(12):2962-2971. doi:10.1093/humrep/deq264

5. Daniels LB, Clopton P, Laughlin GA, et al. Growth-differentiation factor-15 is a robust, independent predictor of 11-year mortality risk in community-dwelling older adults: the Rancho Bernardo Study. Circulation. 2011;123(19):2101-2110. doi:10.1161/CIRCULATIONA HA. 110.979740

6. Mimeault M, Batra SK. Divergent molecular mechanisms underlying pleiotropic functions of macrophage inhibitory cytokine-1 in cancer. J Physiol. 2010;224(3):626-635. doi:10.1002/jcp.22196

7. Park BS, Song DH, Kim HM, Choi BS, Lee H, Lee JO. The structural basis of lipopolysaccharide recognition by the TLR4-MD-2 complex. Nature. 2009;458(7242):1191-1195. doi:10.1038/nature07830

8. Zhang ZF, Fan SH, Zheng YL, et al. Purple sweet potato color attenuates oxidative stress and inflammatory response induced by d-galactose in mouse liver. Food Chem Toxicol. 2008;47 (2):496-501. doi:10.1016/j.fct.2008.12.005

9. Ho SC, Liu JH, Wu RY. Establishment of the mimetic aging effect in mice caused by D-galactose. Biogerontology. 2003;4(1):15-18. doi:10.1023/A:1022417102206

10. Zhang T, Guo WL, Nie ZM, et al. Source identification and quality analysis of Silybum marianum (L.) Gaertn. J Zhejiang Sci-Tech Univ. 2017;37(3):467-474. doi:10.3969/j.issn.1673-3851.2017.05.025

11. Rašković A, Stilinović N, Kolarović J, et al. The protective effects of silymarin against doxorubicin-induced cardiotoxicity and hepatotoxicity in rats. Molecules. 2011;16(10):8601. doi:10.3390/ molecules 16108601

12. Jaggi AS, Singh N. Silymarin and its role in chronic diseases. $A d v$ Exp Med Biol. 2016;929(2):25-44. doi:10.1007/978-3-319-4134262

13. Federico A, Dallio M, Loguercio C. Silymarin/Silybin and chronic liver disease: a marriage of many years. Molecules. 2017;22(2):191. doi:10.3390/molecules22020191

14. Ji RL, Zhao QE. Protective effect of silymarin on carbon tetrachloride induced liver injury in mice. Chin J Appl Physiol. 2012;28(03):279-280 + 287. doi:10.13459/j.cnki.cjap.2012.03.005

15. Li C, Liu H, Yang J, et al. Effect of soybean milk fermented with Lactobacillus plantarum HFY01 isolated from yak yogurt on weight loss and lipid reduction in mice with obesity induced by a high-fat diet. RSC Adv. 2020;10:34276. doi:10.1039/D0RA06977A

16. Brunkhorst FM, Reinhart K. Sepsis therapy: present guidelines and their application. Chirurg. 2008;79(4):306-314. doi:10.1007/s00104008-1486-x

17. Zhou BR, Gumenscheimer M, Freudenberg M, Galanos C. A striking correlation between lethal activity and apoptotic DNA fragmentation of liver in response of D-galactosamine-sensitized mice to a non-lethal amount of lipopolysaccharide. Acta Pharmacol Sin. 2003;24(3):193-198.
18. Gazak R, Walterova D, Kren V. Silybin and silymarin - new and emerging applications in medicine. Curr Med Chem. 2007;14 (3):315-338. doi:10.2174/092986707779941159

19. Liu HL. Silymarin the chemical composition and pharmacological effects of progres. Chin J Ethnomed Ethopharm. 2008;17(7):23-25. doi:10.3969/j.issn.1007-8517.2008.07.012

20. Asghar Z, Masood Z. Evaluation of antioxidant properties of silymarin and its potential to inhibit peroxyl radicals in vitro. Pak J Pharm Sci. 2008;21(3):249-254. doi:10.1016/j.neuro.2008.05.001

21. Kiruthiga PV, Shafreen RB, Pandian KS, et al. Protective effect of silymarin on erythrocyte haemolysate against benzo (a) pyrene and exogenous reactive oxygen species $\left(\mathrm{H}_{2} \mathrm{O}_{2}\right)$ induced oxidative stress. Chemosphere. 2007;68(8):1511-1518. doi:10.1016/j.chemosp here.2007.03.015

22. Kim SH, Oh DS, Oh J, et al. Silymarin prevents restraint stress-induced acute liver injury by ameliorating oxidative stress and reducing inflammatory response. Molecules. 2015;21(4):443. doi:10.3390/molecules2 1040443

23. Wallace S, Vaughn K, Stewart BW, et al. Milk thistle extracts inhibit the oxidation of low-density lipoprotein (LDL) and subsequent scavenger receptor-dependent monocyte adhesion. J Agric Food Chem. 2008;56(11):3966-3972. doi:10.1021/jf703694u

24. Hajiaghamohammadi AA, Ziaee A, Oveisi S, et al. Effects of metformin, pioglitazone, and silymarin treatment on non-alcoholic fatty liver disease: a randomized controlled pilot study. Hepat Mon. 2012;12(8):e6099. doi:10.5812/hepatmon.6099

25. Eraky SM, El-Mesery M, El-Karef A, et al. Silymarin and caffeine combination ameliorates experimentally-induced hepatic fibrosis through down-regulation of LPAR1 expression. Biomed Pharmacother. 2018;101:49-57. doi:10.1016/j.biopha.2018.02.064

26. Pérez HJ, Carrillo SC, García EA, et al. Neuro-protective effect of silymarin in a MPTP mouse model of Parkinson's disease. Toxicology. 2014;319(1):38-43. doi:10.1016/j.tox.2014.02.009

27. Chtourou Y, Fetoui H, Sefi M, et al. Silymarin, a natural antioxidant, protects cerebral cortex against manganese-induced neurotoxicity in adult rats. Biometals. 2010;23(6):985-996. doi:10.1007/s10534-0109345-x

28. Fernández-Moriano C, González-Burgos E, Gómez-Serranillos MP. Mitochondria-targeted protective compounds in Parkinson's and Alzheimer's diseases. Oxid Med Cell Longev. 2015;2015:408927. doi: $10.1155 / 2015 / 408927$

29. Zhao F, Li X. Evaluation of immunomodulatory activity of Silymarin extract from silybum marianum in mice of health food. Adv J Food Sci Technol. 2015;8(4):278-282. doi:10.19026/ajfst.8.1508

30. Okanoue T, Mizuno M. Liver function tests and liver injury - focusing on AST/ALT and PLT count. JAMHTS. 2015;42(2):307-312. doi:10.7143/jhep. 42.307

31. Zelber SS, Ivancovsky WD, Fliss IN, et al. Serum malondialdehyde is associated with non-alcoholic fatty liver and related liver damage differentially in men and women. Antioxidants. 2020;9(7):578. doi:10.3390/antiox 9070578

32. Knowles RG, Merrett M, Salter M, et al. Differential induction of brain, lung and liver nitric oxide synthase by endotoxin in the rat. Biochem J. 1990;270(3):833-836. doi:10.1042/bj2700833

33. Ighodaro OM, Akinloye OA. First line defence antioxidants-superoxide dismutase (SOD), catalase (CAT) and glutathione peroxidase (GPX): their fundamental role in the entire antioxidant defence grid. Alexandria J Med. 2019;54:287-293. doi:10.1016/j.ajme.2017.09.001

34. Yang CM, Luo SF, Hsieh HL, et al. Interleukin-1beta induces ICAM-1 expression enhancing leukocyte adhesion in human rheumatoid arthritis synovial fibroblasts: involvement of ERK, JNK, AP-1, and NF-kappaB. J Cell Physiol. 2010;224(2):516-526. doi: $10.1002 /$ jcp. 22153

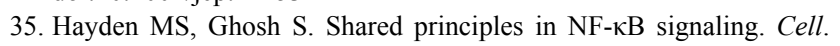
2008;132:344-362. doi:10.1016/j.cell.2008.01.020 
36. Chen Y, Qian Q, Yu J. Carbenoxolone ameliorates insulin sensitivity in obese mice induced by high fat diet via regulating the I $\kappa \mathrm{B}-\alpha / \mathrm{NF}-$ $\kappa \mathrm{B}$ pathway and NLRP3 inflammasome. Biomed Pharmacother. 2019;115:108868. doi:10.1016/j.biopha.2019.108868

37. Cuadrado A, Nebreda AR. Mechanisms and functions of p38 MAPK signalling. Biochem J. 2010;429:403-417. doi:10.1042/BJ20100323

38. Masferrer JL, Zweifel BS, Manning PT, et al. Selective inhibition of inducible cyclooxygenase 2 in vivo is antiinflammatory and nonulcerogenic. Proc Natl Acad Sci U S A. 1994;91(8):3228-3232. doi:10.1073/pnas.91.8.3228

39. He Y, Hara H, Núñez G. Mechanism and regulation of NLRP3 inflammasome activation. Trends Biochem Sci. 2016;41:1012-1021. doi:10.1016/j.tibs.2016.09.002
40. Zhou R, Tardivel A, Thorens B, Choi I, Tschopp J. Thioredoxininteracting protein links oxidative stress to inflammasome activation. Nat Immunol. 2009;11(2):136-140. doi:10.1038/ni.1831

41. Chen B, Lu Y, Chen Y, et al. The role of Nrf2 in oxidative stress-induced endothelial injuries. $J$ Endocrinol. 2015;225 (3):83-99. doi:10.1530/JOE-14-0662

42. Bai ZF, Wang ZJ. Genistein protects against doxorubicin-induced cardiotoxicity through Nrf-2/HO-1 signaling in mice model. Environ Toxicol. 2019;34:645-651. doi:10.1002/tox.22730

\section{Publish your work in this journal}

Drug Design, Development and Therapy is an international, peerreviewed open-access journal that spans the spectrum of drug design and development through to clinical applications. Clinical outcomes, patient safety, and programs for the development and effective, safe, and sustained use of medicines are a feature of the journal, which has also been accepted for indexing on PubMed Central. The manuscript management system is completely online and includes a very quick and fair peer-review system, which is all easy to use. Visit http://www. dovepress.com/testimonials.php to read real quotes from published authors. 